\title{
Spectra of Heliumlike Krypton from Tokamak Fusion Test Reactor Plasmas
}

M. Bitter, H. Hsuan, C. Bush, S. Cohen, C. J. Cummings,

B. Grek, K. W. Hill, J. Schivell, and M. Zarnstorff

Princeton University

Plasma Physics Laboratory

Princeton, NJ 08543

P. Beiersdorfer and A. Osterheld

University of California

Lawrence Livermore National Laboratory

Livermore, CA 94550

A. Smith

Lock Haven University

Lock Haven, PA 17745

B. Fraenkel

Hebrew University

Jerusalem, Israel 


\begin{abstract}
Krypton has been injected into ohmically-heated TFTR plasmas with peak electron temperatures of $6 \mathrm{keV}$ to study the effects of krypton on the plasma performance and to investigate the emitted krypton line radiation, which is of interest for future-generation tokamaks such as ITER, both as a diagnostic of the central ion temperature and for the control of energy release from the plasma by radiative cooling. The emitted radiation was monitored with a bolometer array, an X-ray pulse height analysis system, and a high-resolution Johann-type crystal spectrometer; and it was found to depend very sensitively on the electron temperature profile. Satellite spectra of heliumlike krypton, $\mathrm{KrXXXV}$, near $0.95 \AA$ including lithiumlike, berylliumlike and boronlike fearures were recorded in second order Bragg reflection. Radiative cooling and reduced particle recycling at the plasma edge region were observed as a result of the krypton injection for all investigated discharges. The observations are in reasonable agreement with modeling calculations of the krypton ion charge state distribution including radial transport.
\end{abstract}


Given the large values of the plasma volume $\left(500 \mathrm{~m}^{3}\right)$ and stored energy $(600 \mathrm{MJ})$, which have been specified in the conceptual design of the International Thermonuclear Experimental Reactor (ITER), ${ }^{1}$ the operation of ITER will face two major problems: (1) measurement of the central ion temperature $T_{i}(0),{ }^{2}$ and (2) control of the energy release from the plasma under quasi-continuous conditions with pulse lengths $\geq 1000 \mathrm{sec}$. To control the energy release from the plasma and to reduce the heat load on the plasma-facing components, it has recently been proposed to inject high- $Z$ impurities into the plasma which can provide radiative cooling of the plasma edge region at a rate of $100 \mathrm{MW} \cdot{ }^{3}$ The most likely candidate is krypton $(\mathrm{Z}=$ 36), because it is chemically inert and easily injected in controllable amounts. Krypton can be used to solve both aforementioned problems: the radiation from the high charge state of heliumlike krypton, which will be the dominant state of ionization in the hot core of the plasma for the projected central electron temperatures of $30 \mathrm{keV}$, can be used for Doppler broadening measurements to determine $T_{i}(0)$; and the lower charge states of krypton can provide the required radiative cooling. In order to explore the potential of this experimental approach, it is necessary to study effects of the krypton injection on the plasma performance on present-day large tokamaks and to obtain accurate atomic physics data for all the krypton charge states, e. g., from theoretical calculations and experiments on atomic physics facilities like Electron Beam Ion Traps (EBIT), since these data will be needed for plasma simulation calculations to predict the effects of radiative cooling. Another experimental challenge is the development of efficient crystal spectrometers at wavelengths of $0.95 \AA$, since the high spectral resolution $(\lambda / \Delta \lambda \geq 10000)$ needed for Doppler broadening measurements may only be obtained in second-order Bragg reflection at the expense of a significant reduction in crystal reflectivity. In order to address these questions, which are crucial for the ITER performance as well as for the diagnostic of the central parameters of ITER plasmas, the International Atomic Energy Agency (IAEA) has recommended establishing an atomic physics database on krypton. ${ }^{4}$ Following this recommendation, research programs are now under way to determine wavelengths and rate coefficients for various atomic processes for krypton ions. ${ }^{5}$ In this paper we present first results from krypton experiments on TFTR. These experiments made it possible to study the performance of TFTR plasmas with krypton injection and to obtain a high resolution spectrum of heliumlike krypton, $\mathrm{KrXXXV}$. 
The experiments were conducted with ohmically heated helium discharges at three different plasma currents of $I_{p}=1.4,1.6$ and 1.8 MA. These discharges had electron densities in the range from 1.5 to $2.5 \times 10^{19} \mathrm{~m}^{-3}$ and peak electron temperatures in the range from 5 to $6 \mathrm{keV}$. The radial electron temperature profiles, which are shown in Fig. 1, varied from very peaked profiles for $I_{p}=1.4 \mathrm{MA}$ and $I_{p}=1.6 \mathrm{MA}$ to a wide profile for $I_{p}=1.8 \mathrm{MA}$. Krypton was injected into these discharges at a rate of 0.2-0.35 Torr $\cdot \mathrm{liter} / \mathrm{sec}$ for time intervals of $0.2 \mathrm{sec}$ and $0.25 \mathrm{sec}$, after the plasma had reached steady state conditions. The ionization equilibrium of high- $Z$ elements in tokamak plasmas can be approximated by the so-called coronal equilibrium model, which is only a function of the electron temperature $T_{e}$. For the observed peak electron temperature of $6 \mathrm{keV}$, this model predicts fractional abundances of $53 \%, 30 \%$ and $13 \%$ for the heliumlike, lithiumlike and berylliumlike krypton ions, respectively. 6 In practice, however, substantial deviations from this equilibrium can occur due to radial ion transport. ${ }^{7}$ The intensity of the $1 s^{2}-1 s 2 p$ resonance line of heliumlike krypton is expected to be weak for $T_{e}=6 \mathrm{keV}$, since the excitation rate coefficient for this line varies approximately as $T_{e}-1 / 2 \exp \left(-E_{w} / T_{e}\right)$, where $E_{w}=13 \mathrm{keV}$ is the threshold energy for electron impact excitation.

A survey spectrum of the emitted $X$-ray radiation from a discharge with $I_{p}=1.8 \mathrm{MA}$ is shown in Fig. 2a. The spectrum consists of a bremsstrahlung continuum and $\mathrm{K} \alpha$-line radiation from various ions. The intensity of the $\mathrm{K} \alpha$-line radiation from the injected krypton is comparable with the intensity of the $\mathrm{K} \alpha$-line radiation from spurious metal impurities, $\mathrm{Cr}, \mathrm{Fe}$ and $\mathrm{Ni}$. These measurements were performed with the TFTR X-ray Pulse Height Analysis (PHA) system. 8 Since the energy resolution of the $\mathrm{Si}(\mathrm{Li})$ detectors used by the PHA system is $230 \mathrm{eV}$, the peak at $13 \mathrm{keV}$ includes the $\mathrm{K} \alpha$-line radiation from all the krypton charge states. Crystal spectrometers, which provide higher spectral resolution, are needed to resolve the contribution from the $1 s^{2}-1 s 2 p$ resonance line of heliumlike krypton, $\mathrm{KrXXXV}$. Figure $2 \mathrm{~b}$ shows the observed time evolution of the krypton $\mathrm{K} \alpha$ peak at $13 \mathrm{keV}$ for the investigated ohmic discharges. Since the PHA system is a spectrometer with pinhole apertures having a horizontal sightline through the center of the plasma, the intensity of the krypton $\mathrm{K} \alpha$ peak represents a chord integrated measurement and is expected to increase with the widih of the electron temperature profile which, for our experiments, increased with the value of plasma current (see Fig. 1). From a further analysis of these PHA data, it is 
found that the total krypton density was $\sim 0.1 \%$ of the electron density at the time of the maxima shown in Fig. $2 b$.

Figure 3 shows measurements of the total radiated power loss from the plasma, which were performed with the TFTR bolometer array. 9 The total radiated power before the injection of krypton was about $40 \%$ of the ohmic input power, whereas with the injection of krypton it approached $100 \%$ of the ohmic input power for the discharges with Ip $=1.4 \mathrm{MA}$ and Ip $=1.6$ $\mathrm{MA}$ and $70 \%$ for Ip $=1.8 \mathrm{MA}$. We note that the additional radiated power due to the krypton injection decteased for increasing values of $\mathrm{I}_{\mathrm{p}}$, i.e. $\Delta \mathrm{P}_{\text {rad }} \approx 1 \mathrm{MW}$ for $\mathrm{Ip}=1.4 \mathrm{MA}$ and $\Delta \mathrm{P}_{\text {rad }}$ $\approx 0.6 \mathrm{MW}$ for $\mathrm{Ip}=1.8 \mathrm{MA}$, even though in the latter case a larger amount of krypton was injected. This observation and the aforementioned result that the krypton $\mathrm{K} \alpha$ radiation increased for increasing values of $\mathrm{I}_{\mathrm{p}}$ suggest that, for the broader electron temperature profiles obtained for $I_{p}=1.8 \mathrm{MA}$, the ionization equilibrium was shifted to the higher charge states; the higher charge states emit significantly less line radiation than the lower ionization states. 10 This conclusion is supported by MIST-code ${ }^{11}$ modeling calculations of radial profiles for the krypton ion charge states and the emitted total krypton line radiation. These calculations were based on the measured profiles of the electron temperature and density and assumed a value of $0.1 \%$ for the ratio of the toatal krypton and electron densities as well as a constant diffusion coefficient of $D=1 \mathrm{~m}^{2} / \mathrm{s}$ for all the krypton charge states. The modeling calculations provided the following results: (1) The calculated radial distributions of the krypton ion charge states were distinctly different for the three discharges, e. g. the central densities of heliumlike krypton, $\mathrm{KrXXXV}$, were $0.4 \times 10^{15} \mathrm{~m}^{-3}$ and $2.0 \times 10^{15} \mathrm{~m}^{-3}$ for the discharges with $\mathrm{I}_{\mathrm{p}}=1.4 \mathrm{MA}$ and $\mathrm{I}_{\mathrm{p}}=1.8 \mathrm{MA}$, respectively. (2) The obtained radial profiles of the emitted total krypton line radiation were peaked for the discharges with $I_{p}=1.4 \mathrm{MA}$, but hollow for the discharge with $I_{p}=1.8 \mathrm{MA}$ with distinctly different values for the central emissivities of 32 and $8 \mathrm{~kW} / \mathrm{m}^{3}$, respectively. (3) The volume integrated total power of the krypton line radiation yielded values of $\Delta P_{\text {rad }}=0.96 ; 0.81$; and $0.46 \mathrm{MW}$ for the discharges with Ip $=1.4 ; 1.6$; and $1.8 \mathrm{MA}$, in reasonable agreement with the bolometer measurements. The result (2) may explain the measurements of the electron cyclotron emission (ECE), that showed a noticeable drop of the central electron temperature by $\sim 0.5 \mathrm{keV}$ during the injection of krypton for the discharges with $I_{p}=1.4 \mathrm{MA}$ and $I_{p}=1.6 \mathrm{MA}$ but not for the 
discharges with $I_{p}=1.8 \mathrm{MA}$. For all discharges, the ECE measurements also showed a reduction of the edge electron temperature at $\mathrm{R}=3.30 \mathrm{~m}$ by 10 to $20 \%$ during the injection of krypton. This radiative cooling of the edge plasma was correlated with a reduction of the particle recycling between the wall and the edge plasma as indicated by a density decrease of 5 to $10 \%$ at $R=3.30$ $m$ and a reduction of the edge emitted carbon and $\mathrm{H} \alpha$ light by more than $50 \%$.

High-resolution spectra of krypton near $0.95 \AA$ were observed with one channel of the TFTR Vertical Crystal Spectometer 12 using a $20 \overline{2} 3$ - quartz crystal $(2 \mathrm{~d}=2.7497 \AA$; with a curvature radius of $11.43 \mathrm{~m}$ ) in second order Bragg reflection. This arrangement was chosen to obtain a large Bragg angle of $\Theta=43.7$ degree and thus a high spectral resolution of $\lambda / \Delta \lambda=12000$ needed for Doppler broadening measurements. The reflected photons were detected with a position-sensitive Multi-Wire Proportional Counter (MWPC) using xenon at atmospheric pressure as detector gas. We note that the crystal also reflects in first order photons with energies of 6.5 $\mathrm{keV}$, which are emitted from the bremsstrahlung continuum of the plasma with a comparable or higher intensity than the $13 \mathrm{keV}$ photons of interest (see Fig. 2a). Moreover, the integrated crystal reflectivities for first- and second-order reflection differed by one order of magnitude $\left(R_{c}=\right.$ $4.169 \times 10^{-6} \mathrm{rad}$ for the $6.5 \mathrm{keV}$ photons and $R_{c}=0.4413 \times 10^{-6} \mathrm{rad}$ for the $13 \mathrm{keV}$ photons ${ }^{13}$ ); and the detection efficiency of the MWPC for these photons differed by a factor of 2.5 (100\% and $40 \%$ for the photon energies of 6.5 and $13 \mathrm{keV}$, respectively). It was therefore necessary to attenuate the intensity of the $6.5 \mathrm{keV}$ photons by a factor of about 25 . This was achieved by covering the detector with aluminum foils (total thickness $0.008 \mathrm{in}$ ) which had a transmission of $1.5 \%$ for the $6.5 \mathrm{keV}$ photons and a transmission of $48 \%$ for the $13 \mathrm{keV}$ photons. Figure 4 shows the krypton spectra obtained for $\mathrm{I}_{\mathrm{p}}=1.4$ and $1.8 \mathrm{MA}$. The data were accumulated from 6 and 18 discharges, respectively. The spectrum in Fig. 4a, which was recorded from the discharges with peaked electron temperature profiles (see Fig. 1a), shows only berylliumlike and boronlike features. By contrast, the spectrum in Fig. 4b shows the entire $\mathrm{KrXXXV}$ satellite spectrum consisting of the heliumlike lines $w, x, y, z$ and the associated lithiumlike, berylliumlike and boronlike satellites. These features have been identified using the instrumental dispersion and theoretical wavelengths from Reference 14 as well as from new calculations based on the HULLAC-code; 15 and they are listed in Table I. The key letters in Fig. 4 and Table I correspond 
to Gabriel's notation. 16 Very noticeable is the large relative wavelength separation of the heliumlike features $\mathbf{w}, \mathbf{x}, \mathbf{y}$ and $\mathbf{z}$ and the fact that the positions of the lithiumlike and berylliumlike satellites are much closer to the resonance line $\mathbf{w}$ than in the previously studied spectra of heliumlike TiXXI, CrXXIII, FeXXV and NiXXVII. 17 This is a demonstration of the Z-dependent wavelength shifts in the satellite spectra of heliumlike ions, which were discussed in detail in Reference 18. In particular, the forbidden line $\mathbf{z}$ is well isolated from all the strong lithiumlike and berylliumlike $n=2$ satellites. This line may thus be used for Doppler broadening measurements and may, in fact, be better suited than the resonance line w commonly used for the ion temperature diagnostic on present-day tokamaks. Not only is the intensity of the line $\mathbf{z}$ comparable to that of the line $w$, but it is also uncontaminated by unresolved $n \geq 3$ satellites. 19,20 By contrast, substantial corrections to the width of the KrXXXV resonance line w will be necessary due to the fact that the intensity of unresolved $n \geq 3$ satellites increases with $Z^{4}$. Measurement of the ion temperature from the least squares fit of a single Voigt profile to the $\mathrm{KrXXXV}$ forbidden line $\mathrm{z}$ provided a value of $T_{i}=2.5 \pm 0.4 \mathrm{keV}$, in reasonable agreement with the value of $T_{i}(0)=2.3 \mathrm{keV}$ obtained from the FeXXV resonance line which was simultaneously observed with a different channel of the TFTR Vertical Cirystal Spectrometer. By contrast, the corresponding analysis of the KrXXXV resonance line $w$ gave a substantially larger ion temperature value of $6.5 \pm 0.5 \mathrm{keV}$, which we attribute to the aforementioned blending with unresolved satellites. This broadening by $\mathrm{n} \geq 3$ satellites should, however, be considerably reduced for electron temperatures of $T_{e} \geq 10 \mathrm{keV}$ expected in ITER.

In conclusion, experiments were performed on TFTR to explore the effects of krypton on the plasma performance and to study the emitted line radiation of krypton, which is of interest for future tokamaks, such as ITER, both for the diagnostic of the central ion temperature and for the control of the energy release from the plasma. Bolometer measurements of the total radiated power and measurements of the krypton $\mathrm{K} \alpha$-line radiation indicate that the spectrum of the emitted krypton radiation depends very sensitively on plasma parameters, such as the electron temperature profile. A high-resolution crystal spectrometer was used to measure in second order Bragg reflection the line radiation of the heliumlike, lithiumlike and berylliumlike krypton charge states. In all investigated cases, the ionization equilibrium was far from coronal equilibrium. Heliumlike 
krypton was only marginally present. Nevertheless, it was possible to record for the first time the entire satellite spectrum of $\mathrm{KrXXXV}$. Modeling calculations of the krypton ion charge state . distribution including transport effects and calculations of the total power of the emitted krypton line radiation are in reasonable agreement with the observations. The injection of krypton also produced a decrease of the plasma edge electron temperature and density, indicating effects of radiative cooling and reduced particle recyling at the plasma edge. The $\mathrm{KrXXXV}$ forbidden line $\mathrm{z}$ appears to be free from satellites and therefore well suited for ion temperature measurements. We note that crystal spectrometers could be significantly improved by using doubly-focussing crystals and more efficient detectors. Higher detection efficiency for the $13 \mathrm{keV}$ photons can be achieved by increasing the pressure of the xenon gas in the detector and by including pulse height discrimination circuits to reject photons from the first order Bragg reflection. Theoretical atomic physics studies, experiments on atomic physics facilities, and further tokamak experiments are needed to determine the effects of krypton radiation for different experimental conditions on ITER. These first experimental results from TFTR should stimulate further research in these areas.

We are very grateful to $\mathrm{Dr}$. A. Henins for providing us with information on crystal properties. We also gratefully acknowledge the continuing support of R. J. Hawryluk and K. M. Young as well as the technical assistance of J. Gorman, R. Such and the TFTR operating crew. This work was supported by the U.S. Department of Energy, Contract No. DE-AC02-76-CHO-3073. 
Rêferences

(1) K.Tomabechi et al., Nuclear Fusion 31, 1135 1991); and ITER Documentation Series, No. 23: "ITER Operations and Research Programme", International Atomic Energy Agency, Vienna, 1991 Ion temperature measurements by the techniques of charge exchange recombination spectroscopy (CHERS), which are now widely used and which require the injection of neutral deuterium or tritium beams, may not be feasible on ITER, since (1) present-day -100 keV neutral beams will not penetrate to the core of the plasma; (2) the neutral beam current diminishes at the energies $(>500 \mathrm{keV})$ neede to penetrate to the cor; and (3) the cross-section for CHERS decreases with beam energy.

(3) C. J. Cummings, S. A. Cohen, R. Hulse, D. E. Post and M. Redi, Journal of Nuclear Materials 176\&177,916(1990)

(4) LAEA Technical Committee Meeting on Atomic and Molecular Data for Fusion Reactor Technology, Cadarache, France, October 12-16, 1992

Krypton Experiments on the Electron Beam Ion Trap device at the Lawrence Livermore National Laboratory will be started in 1993 with support of the Department of Energy.

(6) C. Breton, C. De Michelis, M. Finkenthal, and M. Mattioli, Fontenay-aux Roses Laboratory Reort No. EUR-CEA-FC-948, 1978 (unpublished)

(7) M. Bitter, H. Hsuan, V. Decaux, B. Grek, K. W. Hill, R. Hulse, L. A. Kruegel, D. Johnson, S. von Goeler, and M. Zarnstorff, Phys. Rev. A 44, 1796 (1991)

(8) K. W. Hill, M. Bitter, M. Diesso, L. Dudek, S. von Goeler, S. Hayes, L. C. Johnson, J. Kiraly, E. Moshey, G. Renda, S. Sesnic, N. R. Sauthoff, F. Tenney and K. M. Young, Rev. Sci. Instrum. 56, 840 (1985)

(9) J. Schivell, G. Renda, J. Lowrence and H. Hsuan, Rev. Sci. Instrum. 53, 1527 (1982); J. Schivell, Rev. Sci. Instrum. 56, 972 (1985)

(10) D. E. Post, R. V. Jensen, C. B. Tarter, W. H. Grasberger, and W. A. Lokke, At. Data Nucl. Data Tables 20, 397 (1977)

(11) R. A. Hulse, Nucl. Technol. Fusion 3, 259 (1983) 
(12) M. Bitter, K. W. Hill, S. Cohen, S. von Goeler, H. Hsuan, L. C. Johnson, S. Raftopoulos, M. Reale, N. Schechtman, S. Sesnic, F. Spinos, J. Timberlake, S. Weicher, N. Young, and K. M. Young, Rev. Sci. Instrum. 57, 2145 (1986);

(13) A. Henins, National Institute of Standards and Technology, Gaithersburg, Maryland, private communication

(14) L. A. Vainshtein and U. I. Safronova, [Acad. Sci. USSR] P. N. Lebedev Institute of Spectroscopy, Rep. 2, 1985

(15) M. Klapisch, Comput. Phys. Commun.2, 239 (1971); and M. Klapisch, J. L. Schwob, B. S. Fraenkel, and J. Oreg, J. Opt. Soc. Am. 61, 148 (1977)

(16) A. Gabriel, Mon. Not. R. Atron. Soc. 160, 99 (1972)

(17) M. Bitter, H. Hsuan, J. E. Rice, K. W. Hill, M. Diesso, B. Grek, R. Hulse, D. W. Johnson, L. C. Johnson, and S. von Goeler, Rev. Sci. Instrum. 59, 2131 (1988)

(18) TFR group, M. Cornille, J. Dubau, and M. Loulergue, Phys. Rev. A 32, 3000 (1985)

(19) P. Beiersdorfer, S. Chantrenne, M. H. Chen, R. E. Marrs, D. A. Vogel, K. L. Wong, and R. Zasadzinski, Z. Phys. D 211, 209 (1991)

(20) M. Bitter, S. von Goeler, K. W. Hill, R. Horton, D. Johnson, W. Roney, N. Sauthoff, E. Silver, and W. Stodiek, Phys. Rev. Lett. 47, 921 (1981) 
TABLE I: Theoretical wavelengths for the transitions in heliumlike krypton, $\mathrm{KrXXXV}$, and the main $n=2$ satellites from Vainshtein and Safronova (Ref. 14)

\begin{tabular}{|c|c|c|}
\hline Key & Transition & $\begin{array}{c}\text { Wavelength } \\
(\AA)\end{array}$ \\
\hline $\mathbf{w}$ & $1 s^{2}{ }^{1} S_{0}-1 s 2 p{ }^{1} P_{1}$ & 0.94538 \\
\hline $\mathbf{x}$ & $1 s^{2}{ }^{1} S_{0}-1 s 2 p{ }^{3} P_{2}$ & 0.94708 \\
\hline $\mathbf{s}$ & $1 s^{2} 2 s^{2} s_{1 / 2}-1 s 2 p 2 s\left({ }^{3} P\right)^{2} P_{3 / 2}$ & 0.94746 \\
\hline t & $1 s^{2} 2 s^{2} s_{1 / 2}-1 s 2 p 2 s\left({ }^{3} P\right)^{2} P_{1 / 2}$ & 0.94804 \\
\hline$q$ & $1 s^{2} 2 s^{2} S_{1 / 2}-1 s 2 p 2 s\left({ }^{1} P\right)^{2} P_{3 / 2}$ & 0.94961 \\
\hline $\mathbf{k}$ & $1 s^{2} 2 p^{2} P_{1 / 2}-1 s 2 p^{2}{ }^{2} D_{3 / 2}$ & 0.94995 \\
\hline j & $1 s^{2} 2 p^{2} p_{3 / 2} \cdot 1 s 2 p^{2}{ }^{2} D_{5 / 2}$ & 0.95137 \\
\hline $\mathbf{y}$ & $1 s^{2}{ }^{1} S_{0} \cdot 1 s 2 p{ }^{3} P_{1}$ & 0.95156 \\
\hline$r$ & $1 s^{2} 2 s^{2} S_{1 / 2}-1 s 2 p 2 s\left({ }^{1} P\right){ }^{2} P_{1 / 2}$ & 0.95288 \\
\hline$\beta$ & $1 s^{2} 2 s^{2}{ }^{1} S_{0}-1 s 2 p 2 s^{2} 1 P_{1}$ & $0.9529^{*}$ \\
\hline $\mathbf{z}$ & $1 s^{2} 1 s_{0}-1 s 2 s{ }^{3} s_{1}$ & 0.95525 \\
\hline e & $1 s^{2} 2 p^{2} p_{3 / 2}-1 s 2 p^{2}{ }^{4} p_{5 / 2}$ & 0.95615 \\
\hline $\mathrm{u}$ & $1 s^{2} 2 s^{2} S_{1 / 2}-1 s 2 s 2 p\left({ }^{3} P\right)^{4} P_{3 / 2}$ & 0.95652 \\
\hline
\end{tabular}

*from present calculations 


\section{Figure Captions}

Fig. 1 Radial profiles of the electron temperature of ohmically heated TFTR plasmas with different plasma currents: (a) $I_{p}=1.4 \mathrm{MA}$, (b) $I_{p}=1.6 \mathrm{MA}$ and (c) $I_{p}=1.8 \mathrm{MA}$. The data were obtained from Laser Thomson scattering measurements.

Fig. 2 Results from the TFTR X-ray Pulse Height Analysis system: (a) X-ray spectrum consisting of the bremsstrahlung continuum and $\mathrm{K} \alpha$ line radiation from $\mathrm{Cr}, \mathrm{Fe}, \mathrm{Ni}$ and $\mathrm{Kr}$, (b) time evolution of the krypton $\mathrm{K} \alpha$ peak, where $\mathrm{t}=0$ corresponds to the starting time of the krypton injection.

Fig. 3 Total radiated power as measured by a bolometer array for (a) $I_{p}=1.4 \mathrm{MA}$, (b) $I_{p}$ $=1.6 \mathrm{MA}$ amd (c) $\mathrm{I}_{\mathrm{p}}=1.8 \mathrm{MA}$. The dotted lines represent data from comparison discharges without krypton injection.

Fig. 4 Krypton $\mathrm{K} \alpha$ spectra as measured from one channel of the TFTR Vertical Crystal Spectrometer with a vertical sightline through the center of the vacuum vessel at $R_{0}=$ $2.65 \mathrm{~m}$. The data were accumulated (a) for 6 nearly identical ohmic discharges with Ip $=1.4 \mathrm{MA}$, and (b) for 18 nearly identical ohmic discharges with Ip = 1.8 MA. 

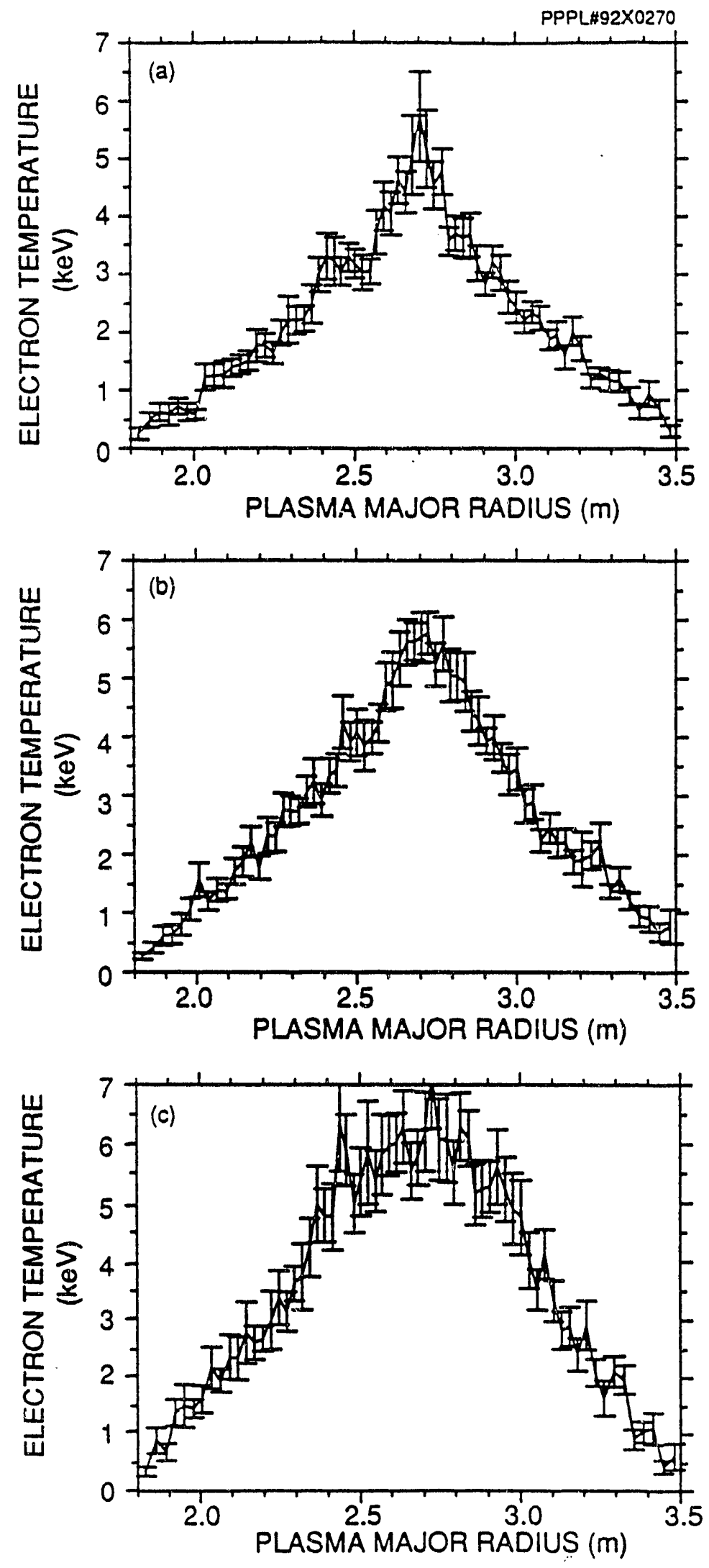

Fig. I 

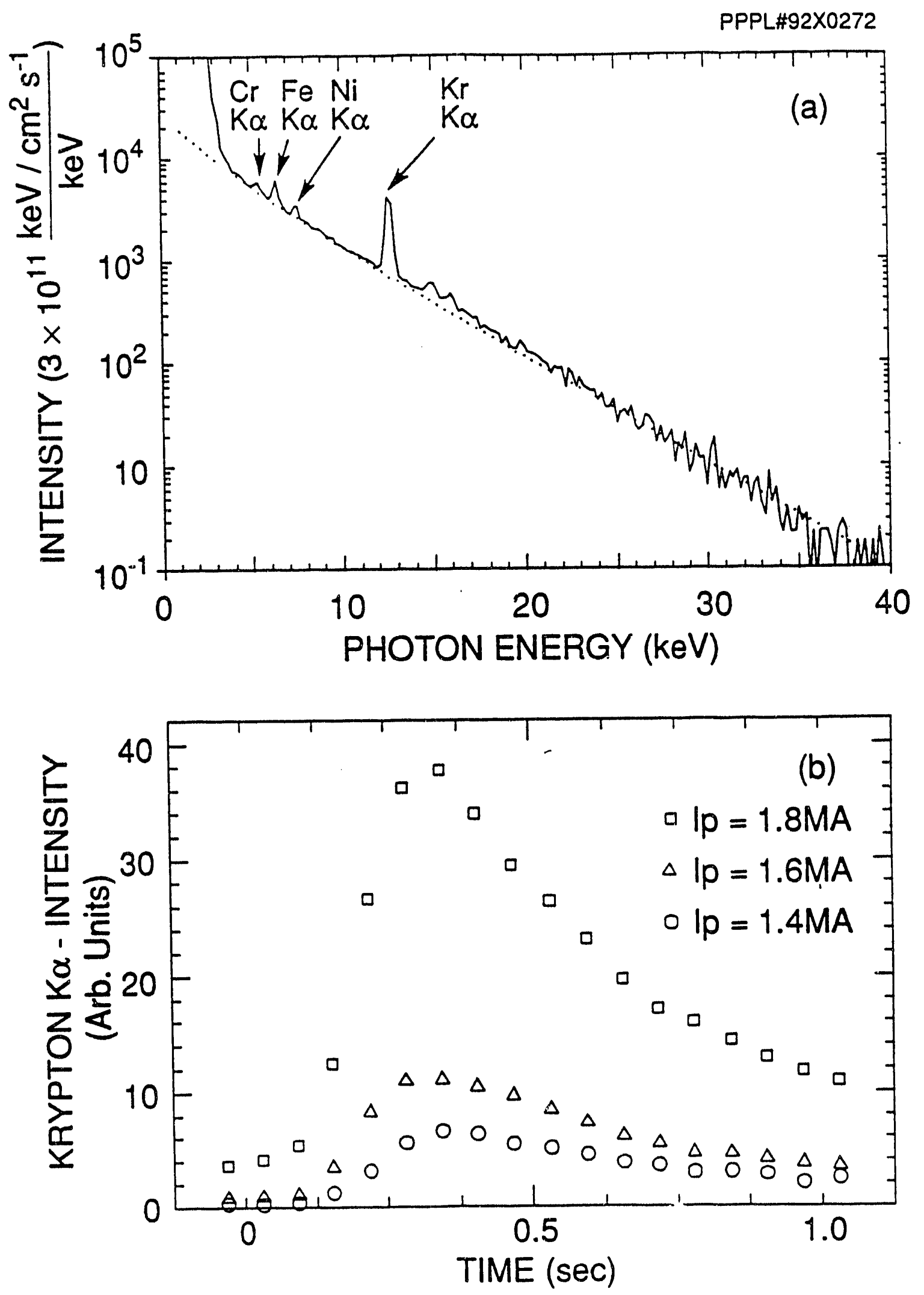

Fig. 2 

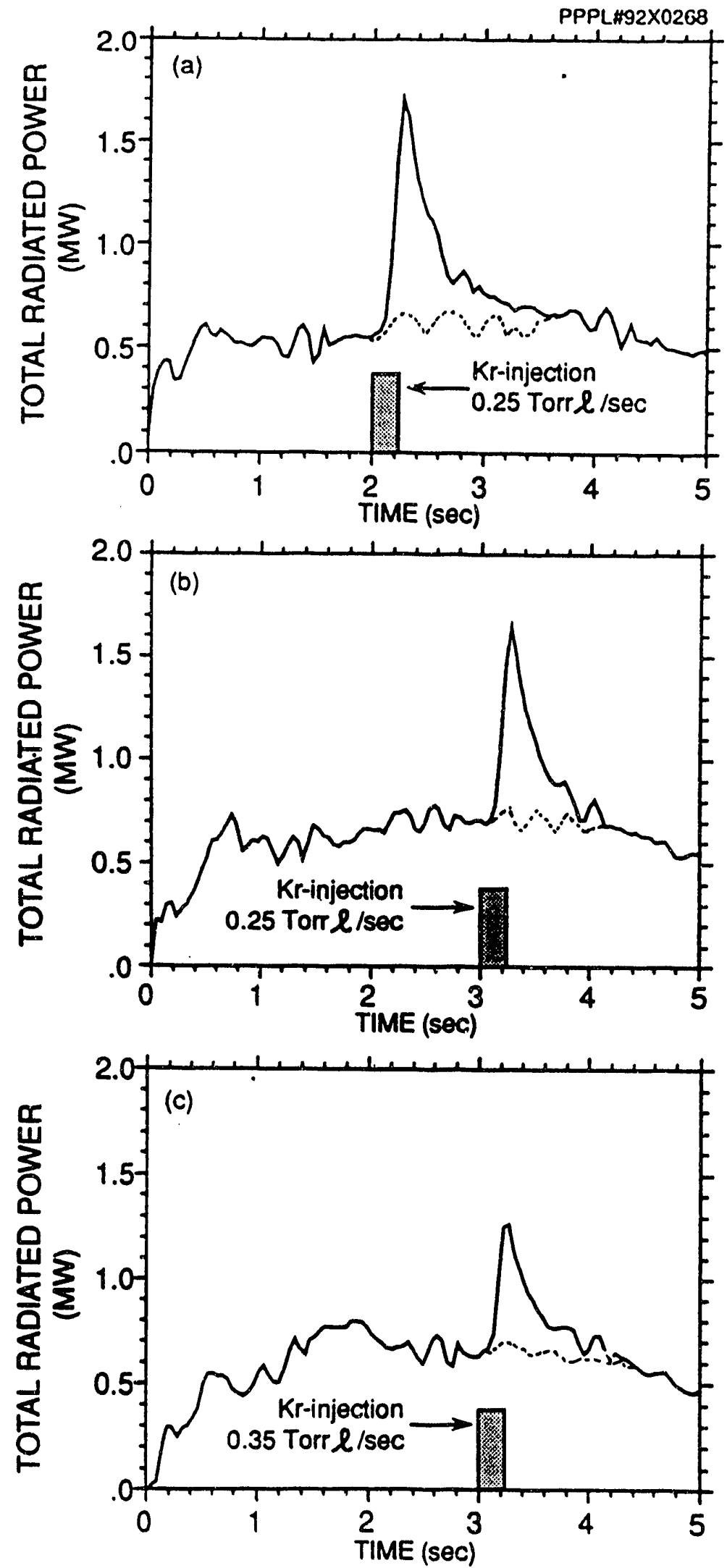

Fig. 3 

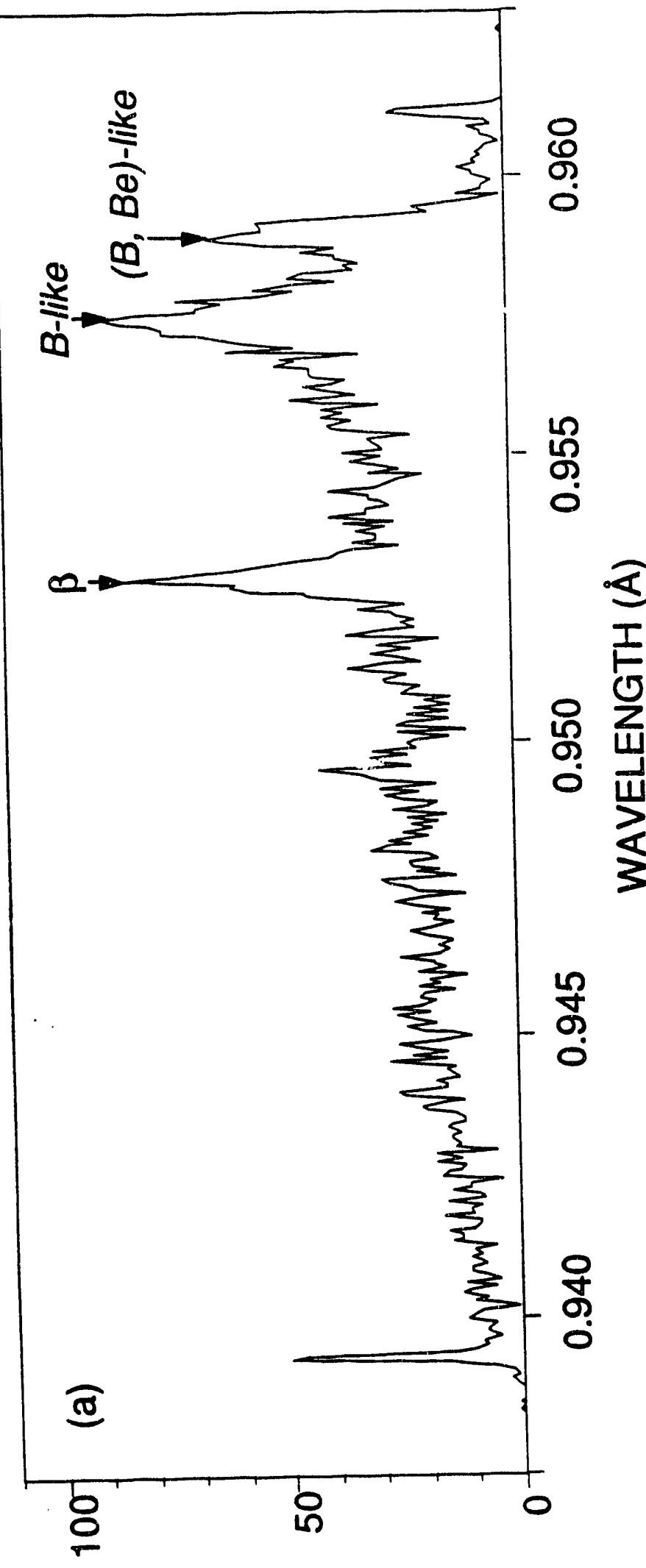

4
0
0

$\frac{3}{\frac{1}{5}}$

SINNOO NOLOHd

\&
ด

e

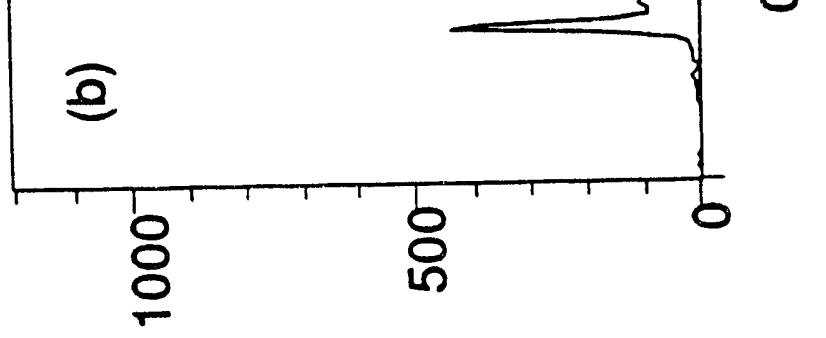

18

के

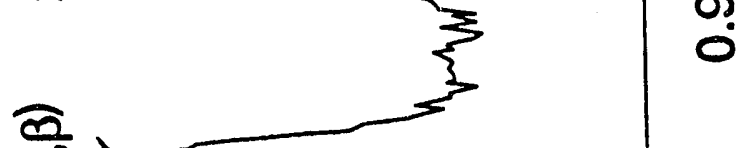

$\frac{5}{1}$

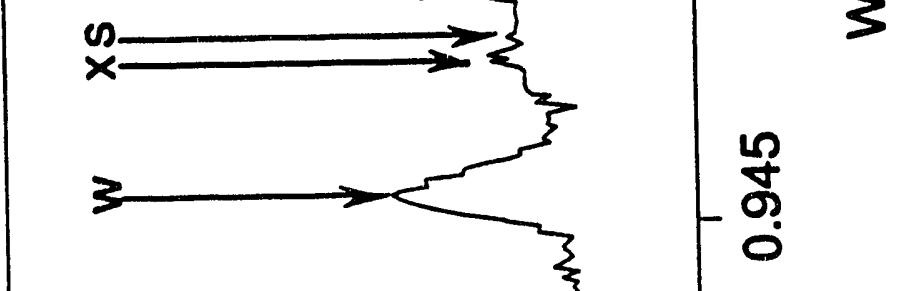

SINOOO NOLOHd

Fig. 4 
Dr. F. Peoloni, Univ. of Wollongong, AUSTRALIA

Prof. M.H. Brennan, Univ. of Sydney, AUSTRALIA

Plasma Research Lab., Australien Nat. Univ., AUSTRALIA

Prof. I.R. Jones, Finders Univ, AUSTRALIA

Prot. F. Cep, Inst for Theoretical Physics, AUSTRIA

Prof. M. Heindier, Institut for Theoretieche Phyeik, AUSTRIA

Prof. M. Gooseons, Astronomiech InstituUt, BELGIUM

Ecole Poyedo Mibtein, Lab. Phy. Plaemas, BELGIUM

Commiscion-Europen, DG. XII-Fusion Prog., BELGIUM

Prof. R. Bouciqub, Rikcuniverditit Gent, BELGIUM

Dr. P.H. Salemati, Inatuso Fica, BANZL

Instiuto Neciond Do Pesquiass Espaciaie-INPE, ERUZIL

Documents Oilion, Alomic Energy of Cenade Lel., CANADA

Dr. M.P. Bachynaki, MPB Technologios. Inc., CANADA

Dr. H.M. Skersogrd, Univ. of Secketatrowen, CANADA

Prof. J. Toichmann, Univ. of Montred, CANAOA

Prot. S.R. Sremivean, Univ. of Coloery, CANADA

Prof. T.W. Johneton, INRS-Enorgio, CANADA

Dr. R. Bovion, Contre canadien de tusion magnblique, CANADA

Dr. C.R. James, Univ. of Alowra, CANAOA

Dr. P. Lukte, Komenaktho Univerasth, CZECHOSLOVAKIA

Tho Librerien, Cuham Leborabry, ENCLAND

Librery, R81, Ruthertord Appieton Laboratory, ENCLAND

Mre. S.A. Hutchineon, JET Lionry, ENGLAND

Dr. S.C. Shama, Univ. of Soum Profic, FWII ISLANDS

P. Munonen, Univ. of Holeindi, FINLAND

Prot. M.N. Buacec, Ecodo Polysuchnique., FRANCE

C. Mouter, Lab. do Phycique des Millioux loniect, FRANCE

J. Padbe, CENCADARACHE - Bat 506, FrANCE

Prof. E. Economou, Univ. of Crm. GPEECE

M. C. Rimi, Univ. of lomina, CAEECE

Dr. T. Mud, Acodinny Ebilooraphic Ser., HONO KONG

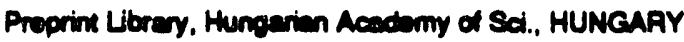

Dr. B. Descupta, Saha inat of Nucteer Physices, INDIA

Dr. P. Kaw, Inat. for Pleama Rasoarch, INOLA

Dr. P. Rocenew, lereal inst of Technology, ISPAEL

Librerien, Intemationd Conter for Theo Physics, ITALY

Niss C. Do Paio, Associazion EURATOALNEA, ITALY

Dr. G. Groseo, latuto d Ficica del Plaema, ITALY

Prof. G. Postanoni, latture Gas lonizzedi DN Cnr, ITALY

Dr. H. Yemes, Tomion Rase Devel Center, JAPAN
Prot. I. Kewakemi, Hirochima Univ., JAPAN

Prof. K. Nishikawe, Hiroshima Univ., JAPAN

Director, Jepen Atomic Enoroy Rosearch Inst, JAPAN

Prot. S. Ioh, Kyushu Univ., LAPAN

Poswarch Info. Ctr., Nationd Instit. for Fusion Science, JAPAN

Prof. S. Tenatia, Kyoto Univ., JAPAN

Librery, Kyob Univ., JAPAN

Prot. N. Inowe, Univ. of Tokyo, LAPAN

Secretery, Plemena Suction, Eloctrowechnical Lab., JAPAN

S. Mori, Tectrical Advieor, LAERI, LAPAN

Dr. O. Murd, Kumenots hat of Technology, JAPAN

J. Hyeon-Sook, Korsa Alomic Enorgy Posearch Inst, KOREA

D.I. Chai, The Korne Adv. Inst. of Sai. \& Tech., KOREA

Prol. B.S. Liby, Univ. of Weikab, NEW ZEALAND

Intt of Phyrics, Chinees Acad SA PEOPLE'S REP. OF CHINA

Librery, Inst of Plaema Physics, PEOPLE'S REP. OF CHINA

Teinohua Univ. Library, PEOPLE'S REPUBLIC OF CHINA

Z. Li, S.W. Inat Phyeics, PEOPLE'S REPUBUC OF CHINA

Prof. J.A.C. Cebrd, Institusto SUperior Teconico, PORTUGAL

Dr. O. Purus, Al I CUzA Univ., ROMANIA

Dr. J. do Viviers, Fution Studies, AEC, S. AFRICA

Prot. M.A. Hemberg. Univ. of Mated, S. AFRICA

Prot. D.E. Km, Poheng ind. of Sa. \& Tech., SO. KOPEA

Prot. C.I.E.MA.T, Fuaion Divition Libray, SPAN

Dr. L SWmino, Univ. of UMEA, SWEDEN

Librery, Royed Inct. of Techrology, SWEDEN

Prot. H. Whatmeon, Chemers Univ. of Tech., SWEDEN

Contre Phys. Des Plasmas, Ecolo Potytech, SWITZERLANO

Biblictheak, Inst. Voor Plasma-Fycica, THE NETHERLANDS

Aast Prot. Dr. S. Calkir, Midd Eest Tech. Univ., TURKEY

Dr. V.A. Culthilh, Sai. Ras. Inst Eloctrophys. I Apperatus, USSR

Dr. D.D. Aurtov, Siberien Brench of Academy of Sal., USSA

Dr. OA. Eieser, I.V. Kurchatov Inst, USSP

Libreien, The Ukr.SSA Academy of Sciences, USSA

Dr. LM. Kowizinnykh, Inat. of Ganard Phyaica, USSA

Kontonchungeaniago GmbH, Zentrabibliothek, W. GERMANY

Bibliothak, Inat. FOr Plasmatorechung, W. GERMANY

Prof. K. Schindior, Ruhr-Universite Bochum, W. GERMANY

D. F. Wegrer, (ASDEX), Max-Plenck-Inatitut, W. GERMANY

Libreion, Max-Plenck-Instient, W. GERMANY

Prot. R.K. Janev, Inat of Phycios, rucoslavia 
DATE

FILMED

$5 / 28 / 93$ 
